Pesq. Vet. Bras. 36(10):957-964, outubro 2016 DOI: 10.1590/S0100-736X2016001000007

\title{
Caracterização molecular de Listeria monocytogenes oriundas de cortes cárneos bovinos e de abatedouros frigoríficos de bovinos localizados no Distrito Federal, Brasil ${ }^{1}$
}

\author{
Joana M. Palma ${ }^{2 *}$, Rodrigo C. Lisboa ${ }^{3}$, Dália P. Rodrigues ${ }^{3}$, André F.M. Santos ${ }^{4}$, \\ Ernesto Hofer ${ }^{4}$ e Angela P. Santana ${ }^{2}$
}

\begin{abstract}
Palma J.M., Lisboa R.C., Rodrigues D.P., Santos A.F.M., Hofer E. \& Santana A.P. 2016. [Molecular characterization of Listeria monocytogenes from beef samples and cattle slaughterhouses located in the Federal District, Brazil.] Caracterização molecular de Listeria monocytogenes oriundas de cortes cárneos bovinos e de abatedouros frigoríficos de bovinos localizados no Distrito Federal, Brasil. Pesquisa Veterinária Brasileira 36(10):957-964. Faculdade de Agronomia e Medicina Veterinária, Universidade de Brasília, Brasília, DF 70910-900, Brazil. E-mail: joanamarchesini@gmail.com

The aim of the study was the analysis of Listeria monocytogenes strains in beef samples as well as slaughterhouse environment, located in the Federal District, promote serotyping by polymerase chain reaction (PCR), perform antibiotic susceptibility and submit the strains to Pulsed-field gel electrophoresis (PFGE). A total of 125 beef samples were analyzed, 45 samples of carcasses swabs and 43 swab samples. It detected 13 strains of Listeria monocytogenes, 11 in beef samples. and 2 in slaughterhouse environment. No carcass swabs strains were isolated. Among the 13 strains of L. monocytogenes six strains of serotype $4 \mathrm{~b}$ were found, five serotype $1 / 2 \mathrm{c}$ and two strains of serotype $1 / 2 \mathrm{a}$. Among the 11 strains of L. monocytogenes found in beef, one (9.1\%) strain showed resistance to erythromycin, one (9.1\%) strain to gentamicin, one to ciprofloxacin $(9.1 \%)$ and all strains $(100 \%)$ were resistant to nalidixic acid. The two strains coming from the slaughterhouse drains, all $(100 \%)$ were resistant to nalidixic acid and Sulfonamides. The analysis by pulsed field gel electrophoresis (PFGE) showed 13 different pulsotypes; they were grouped into three different clonal groups, coincidentally correlated with the three different serotypes found, what suggests a widespread dissemination of these profiles in the Federal District, Brazil.
\end{abstract}

INDEX TERMS: Listeria monocytogenes, pulsed-field gel electrophoresis, PFGE, listeriosis, meat, antibiogram.

RESUMO.- Este trabalho teve como objetivo realizar a detecção de cepas de Listeria monocytogenes de cortes cárneos bovinos bem como no ambiente de abatedouros frigoríficos localizados no Distrito Federal, promover a sorotipificação pela reação em cadeia da polimerase (PCR), realizar antibiograma e submeter às cepas à eletrofore-

\footnotetext{
${ }^{1}$ Recebido em 15 de Janeiro de 2015.

Aceito em 25 de Junho de 2016.

${ }^{2}$ Faculdade de Agronomia e Medicina Veterinária, Universidade de Brasília (UnB), Brasília, DF 70910-900, Brasil. *Autor para correspondência: joanamarchesini@gmail.com

${ }^{3}$ Fundação Oswaldo Cruz (Fiocruz), Av. Brasil 4365, Manguinhos, Castelo Mourisco, sala 13, Rio de Janeiro, RJ 21040-900, Brasil.

${ }^{4}$ Laboratório de Zoonoses Bacterianas, Instituto Oswaldo Cruz (IOC), Fundação Oswaldo Cruz (Fiocruz), Rio de Janeiro, RJ 21040-900, Brasil.
}

se de campo pulsado (Pulsed-field gel electrophoresis PFGE). Foram analisados um total de 125 cortes cárneos bovinos, 45 amostras de swabs de carcaças e 43 amostras de swabs em que foram detectados 13 cepas de Listeria monocytogenes, sendo 11 em cortes cárneos bovinos e 2 swabs de ambiente em um abatedouro frigorifico. Não foram isoladas cepas de swabs de carcaça. Dentre as 13 cepas de Listeria monocytogenes foram encontradas seis cepas do sorotipo $4 \mathrm{~b}$, cinco do sorotipo 1/2c e duas cepas do sorotipo 1/2a. Dentre as 11 cepas de L. monocytogenes encontradas em cortes cárneos bovino, uma $(9,1 \%)$ cepa apresentou resistência a eritromicina, outra $(9,1 \%)$ cepa a gentamicina e outra a ciprofloxacina $(9,1 \%)$ e todas as cepas $(100 \%)$ apresentaram resistência ao Ác. Nalidíxico. Das duas (2) cepas oriundas de ralos de abatedouro frigorífico, 
todas $(100 \%)$ apresentaram resistência ao Ác. Nalidíxico e a sulfonamidas. A análise por eletroforese de campo pulsante (PFGE) demonstrou 13 diferentes pulsotipos, em que foram agrupados em 3 diferentes grupos clonais, que coincidentemente se correlacionavam com os 3 diferentes sorotipos encontrados sugerindo uma ampla disseminação desses perfis no Distrito Federal.

TERMOS DE INDEXAÇÃO: Listeria monocytogenes, eletroforese em campo pulsado (PFGE), listeriose, carne, antibiograma.

\section{INTRODUÇÃO}

0 gênero Listeria é constituído por bactérias gram positivas das espécies Listeria grayi, L. innocua, L. ivanovii, L. seeligeri, L. welshimeri e L. monocytogenes. Destas, a ultima é descrita como patogênica para humanos (Scarcelli \& Piatti 2002). A doença causada por este tipo de bactéria é denominada listeriose e é veiculado principalmente por alimento (Lecuit 2007, Gallegos et al. 2008, Vanegas et al. 2009). Ela possui 13 sorotipos, dentre esses, quatro sorotipos $4 \mathrm{~b}, 1 / 2 \mathrm{a}, 1 / 2 \mathrm{~b}$ e 1/2c são responsáveis por mais de $95 \%$ dos casos clínicos de listeriose em humanos (Cartwright et al. 2013).

A Listeria monocytogenes normalmente é sensível à maioria dos antibióticos exceto a cefalosporinas e fosfomicina, em que são naturalmente resistentes (Troxler et al. 2000). Mas devido à utilização indiscriminada dos antimicrobianos na criação de animais de produção em todo o mundo, existe um interesse global referente ao aumento do número de bactérias resistentes às drogas (Mantilla et al. 2007). No Brasil alguns estudos já foram feitos para conhecer o perfil de resistências para Listeria, como por exemplo, estudos feitos por Moreno et al. (2014) em ambientes de matadouros, carne de porco e infecções humanas que já confirmaram o surgimento de cepas de Listeria resistentes a um ou mais antibióticos.

A caracterização microbiológica da Listeria monocytogenes pode ser realizada pela determinação do sorogrupo (Borucki et al. 2003, Doumith et al. 2004, Chen \& Knabel 2007, Kerouanton et al. 2010b) e também pela eletroforese em gel de campo epulsante (PFGE) com enzimas AscI e Apal (Graves \& Swaminathan 2001, Martin et al. 2006), que por sua vez é considerado o método padrão ouro para subtipagem e atualmente é reconhecida como a mais importante técnica de tipificação para L. monocytogenes (Wiedmann 2002), devido ao seu alto poder discriminatório e reprodutibilidade (Gerner-Smidt et al. 2006). Essa técnica também pode permitir a identificação de pulsotipos específicos que não puderam ser diferenciados previamente pela sorotipificação (Borucki et al. 2004). No Brasil há relatos da utilização desta técnica em cepas de Listeria monocytogenes detectadas em diferentes tipos de alimentos bem como em casos clínicos (Galvão et al. 2012, Camargo 2013, Barbosa et al. 2015), porém no Distrito Federal essa técnica em cepas de Listeria ainda é pouco usada, restringindo-se à cepas oriundas de casos clínicos.

Levando-se em consideração a relevância deste microrganismo para a saúde pública, aos poucos trabalhos realizados com Listeria no Distrito Federal oriundas de alimentos e indústrias de alimentos de origem animal, este trabalho teve por objetivo realizar a detecção de cepas de Listeria monocytogenes de cortes cárneos bovinos bem como no ambiente de abatedouros frigoríficos localizados no Distrito Federal, promover a sorotipificação por PCR, realizar antibiograma, bem como submeter às cepas à eletroforese de campo pulsado (Pulsed-field gel electrophoresis - PFGE).

\section{MATERIAL E MÉTODOS}

Amostragem. Foram analisadas um total de 125 cortes cárneos bovinos no período de março de 2014 a janeiro de 2015, que foram obtidas em 30 diferentes estabelecimentos comerciais dentro do Distrito Federal. A aquisição das amostras simulou uma situação real de compra do consumidor, atentando para embalagens íntegras e com selo de inspeção veterinária federal. Quarenta e cinco (45) amostras de swabs de meias carcaças bovinas, sendo 15 obtidas anteriormente à etapa da lavagem final para resfriamento, 15 obtidos logo após a lavagem final e 15 após 24 horas de permanência em câmara de resfriamento de carcaças. Os locais escolhidos para a obtenção dos swabs nas meias carcaças foram realizados segundo os protocolos descrito por Jardim et al. (2006), em que foram demarcadas com moldes estéreis confeccionados de aço inoxidável com área delimitada de $10 \mathrm{~cm}^{2}$ (um molde para cada ponto). Foram considerados três locais para a coleta das amostras sem meias carcaças bovinas: região do coxão, lombo e ponta de agulha. Os swabs foram obtidos conforme a Associação Brasileira de Normas Técnicas - ABNT (1988), realizando a técnica de esfregaço de superfícies em meias carcaças com auxílio de swabs com ponta em algodão hidrófilo esterilizados. Após a aplicação nos três pontos estudados, os mesmos foram introduzidos em tubos contendo $20 \mathrm{~mL}$ de água peptonada a $0,1 \%$ (solução de transporte). Foram obtidos quarenta e três (43) amostras de swabs de ambientes em abatedouros frigoríficos de bovinos, sendo 14 amostras oriundas da parede da câmara frigorífica, 11 amostras de swabs de ralos de escoamento localizados dentro dos abatedouros frigoríficos, 10 da mesa de inspeção e 8 amostras de swabs oriundos dos pisos de uma única sala de abate A técnica utilizada para colheita de amostras foi a do esfregaço de superfície com swabs em água peptonada $1 \%$ e utilizando moldes estéreis de $10 \mathrm{~cm}^{2}$ (ABNT 1988).

Todas as amostras foram acondicionadas em caixas isotérmicas e encaminhadas ao Laboratório de Microbiologia dos Alimentos (Lamal) da Faculdade de Agronomia e Medicina Veterinária da Universidade de Brasília, em no máximo 1 hora e processadas imediatamente após a chegada ao local.

Isolamento microbiológico nas amostras de carne. A metodologia de isolamento microbiológico utilizada foi a descrita pela Instrução Normativa no. 40 de 2005, do Ministério da Agricultura, Pecuária e Abastecimento - MAPA (Brasil 2005), bem como a descrita por Silva et al. (1997), em que $25 \mathrm{~g} \pm 1,0 \mathrm{~g}$ das amostras de carne bovina foram pesadas em sacos de homogeneização estéreis, sendo adicionados $225 \mathrm{~mL}$ de caldo UVM (Acumedia ${ }^{\circledR}$ )para incubação a $30^{\circ} \mathrm{C} \pm 2^{\circ} \mathrm{C}$ por 24 horas. Em seguida, transferiu-se $0,1 \mathrm{~mL}$ do caldo UVM para $10 \mathrm{ml}$ de caldo Fraser (Acumedia ${ }^{\circledR}$ ) que foram incubados a $35^{\circ} \mathrm{C}$ por $26 \mathrm{~h}$ e por fim distribuiu-se $0,1 \mathrm{~mL}$ do caldo Fraser, que apresentava hidrólise da esculina, para uma placa de ágar MOX (Difco $\left.{ }^{\circledR}\right)$, suplementado com colistina e moxalactam) e incubados a $35^{\circ} \mathrm{C}$ em estufa bacteriológica (Quimis ${ }^{\circledR}$ ) por $24 \mathrm{~h}$, as colônias típicas foram submetidas à coloração de Gram e identificação por testes bioquímicos padrão tais como, teste de catalase e motilidade a $25^{\circ} \mathrm{C}$ e $37^{\circ} \mathrm{C}$. Para a identificação e confirmação da espécie Listeria monocytogenes, foi utilizada a técnica de Reação de Polimerase em Cadeia (PCR) (MyCycler -Bio-Rad), descrita por Kerouanton et al. (2010a). 
Quadro 1. Sequências de oligonucleotídeos utilizados

\begin{tabular}{|c|c|c|c|c|}
\hline Gene alvo & Sequência dos primers ( $\left.5^{\prime}-3^{\prime}\right)$ & $\begin{array}{l}\text { Tamanho do } \\
\text { produto (bp) }\end{array}$ & Especificidade do sorotipo & Referência \\
\hline $\operatorname{lmo} 0737$ & $\begin{array}{l}\text { For: AGGGCTTCAAGGACTTACCC } \\
\text { Rev: ACGATTTCTGCTTGCCATTC }\end{array}$ & 691 & $\begin{array}{l}\text { L. monocytogenes sorotipos } \\
1 / 2 \mathrm{a}, 1 / 2 \mathrm{c}, 3 \mathrm{a} \text { e } 3 \mathrm{c}\end{array}$ & $\begin{array}{l}\text { Doumith et al. } \\
\text { (2004) }\end{array}$ \\
\hline Imo1118 & $\begin{array}{l}\text { For: AGGGGTCTTAAATCCTGGAA } \\
\text { Rev: CGGCTTGTTCGGCATACTTA }\end{array}$ & 906 & $\begin{array}{l}\text { L. monocytogenes sorotipos } \\
1 / 2 \mathrm{c} \text { and } 3 \mathrm{c}\end{array}$ & $\begin{array}{l}\text { Doumith et al. } \\
\text { (2004) }\end{array}$ \\
\hline ORF2819 & $\begin{array}{l}\text { For: AGCAAAATGCCAAAACTCGT } \\
\text { Rev: CATCACTAAAGCCTCCCATTG }\end{array}$ & 471 & $\begin{array}{l}\text { L. monocytogenes sorotipos } \\
\qquad 1 / 2 \mathrm{~b}, 3 \mathrm{~b}, 4 \mathrm{~b}, 4 \mathrm{~d} \text { e } 4 \mathrm{e}\end{array}$ & $\begin{array}{l}\text { Doumith et al. } \\
\text { (2004) }\end{array}$ \\
\hline ORF2110 & $\begin{array}{l}\text { For: AGTGGACAATTGATTGGTGAA } \\
\text { Rev: CATCCATCCCTTACTTTGGAC }\end{array}$ & 597 & $\begin{array}{l}\text { L. monocytogenes sorotipos } \\
\qquad 4 \mathrm{~b}, 4 \mathrm{~d} \text { e } 4 \mathrm{e}\end{array}$ & $\begin{array}{l}\text { Doumith et al. } \\
\text { (2004) }\end{array}$ \\
\hline prs & $\begin{array}{l}\text { For: GCTGAAGAGATTGCGAAAGAAG } \\
\text { Rev: CAAAGAAACCTTGGATTTGCGG }\end{array}$ & 370 & Todos espécies de Listeria & $\begin{array}{l}\text { Doumith et al. } \\
\text { (2004) }\end{array}$ \\
\hline
\end{tabular}

Para a realização do isolamento microbiológico de amostras ambientais foram coletadas por meio de $s w a b$ individuais, friccionados em uma área de $30 \mathrm{~cm}^{2}$. Após a coleta das amostras, os swabs foram acondicionados, individualmente, em tubos contendo $10 \mathrm{~mL}$ de água peptonada à concentração de $0,1 \%$ e transportadas até o Laboratório de Microbiologia dos Alimentos (Lamal) da Faculdade de Agronomia e Medicina Veterinária da Universidade de Brasília, em caixas isotérmicas e foram analisadas em até 24 horas pós-coleta, seguindo as normas descritas pela Instrução Normativa n. 40 de 2005, do Ministério da Agricultura, Pecuária e Abastecimento - MAPA (Brasil 2005).

Sorotipificação. As cepas de Listeria monocytogenes foram sorotipificadas pela técnica da reação em cadeia da polimerase (PCR), no Laboratório de Microbiologia dos Alimentos (Lamal), da Faculdade de Agronomia e Medicina Veterinária, da Universidade de Brasília. O PCR foi realizado com temperaturas de desnaturação de $94^{\circ} \mathrm{C}$ durante $3 \mathrm{~min} ; 35$ ciclos de $94^{\circ} \mathrm{C}$ para $0,40 \mathrm{~min}, 53^{\circ} \mathrm{C}$ durante $1,15 \mathrm{~min}$, e $72^{\circ} \mathrm{C}$ durante $1,15 \mathrm{~min}$; e um último ciclo de $72^{\circ} \mathrm{C}$ durante 7 minutos no termociclador (MyCycler -Bio-Rad), conforme as recomendações descritas por Doumith et al. (2004) e os primers utilizados estão descritos no Quadro 1.

Teste de resistência aos antimicrobianos. Os testes de susceptibilidade antimicrobiana das cepas de Listeria monocytogenes foram realizados pelo método de difusão de disco, seguindo as orientações da Clinical \& Laboratory Standards Institute (CLSI 2012) e para cada colônia isolada foi utilizada as seguintes bases farmacológicas: ácidonalidíxico (NAL: $30 \mu \mathrm{g}$ ), amoxicilina (AMX: $10 \mu \mathrm{g}$ ), ampicilina (AMP: $10 \mu \mathrm{g}$ ), ciprofloxacino (CIP: $5 \mu \mathrm{g}$ ), cloran-

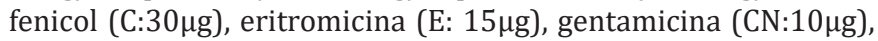
norfloxacino (NOR: $10 \mu \mathrm{g}$ ), penicilina (10U), sulfonamidas (SUL: $300 \mu \mathrm{g}$ ), tetraciclina (TE: $30 \mu \mathrm{g}$ ), vancomicina (VA: $5 \mu \mathrm{g}$ ). As cepas isoladas foram cultivadas em caldo brain heart infusion - BHI (Di$\left.\mathrm{fco}^{\circledR}\right)$, e posteriormente transferidas para ágar de Mueller-Hinton (Oxoid CM 337), e incubadas em estufa bacteriológica (Quimis ${ }^{\circledR}$ ) a $37^{\circ} \mathrm{C}$ durante $48 \mathrm{~h}$. Após esse período foram realizadas as leituras dos resultados, medindo-se o tamanho das zonas de inibição de crescimento bacteriano com um halômetro, sendo a cepa bacteriana classificada como resistente intermediário e sensível, de acordo com o diâmetro da zona padrão estabelecida pelo CLSI (2012).

Eletroforese de campo pulsante (PFGE). As 13 cepas de Listeria monocytogenes foram levadas ao Laboratório de Enterobactérias (Labent) da Fundação Oswaldo Cruz, Rio de Janeiro, para serem submetidas à eletroforese em campo pulsante (PFGE). Todas as culturas obtidas foram submetidas à extração de DNA cromossomal de acordo com o protocolo recomendado pelo Center for Diseases Control and Prevention - CDC (PulseNet 2009) para subtipagem de Listeria monocytogenes (Graves \& Swaminathan 2001) e a digestão enzimática foi realizada utilizando a enzima
Quadro 2. Sorotipificação de Listeria monocytogenes isoladas no Distrito Federal

\begin{tabular}{lcc}
\hline $\begin{array}{l}\text { Origem das cepas } \\
\text { de L. monocytogenes }\end{array}$ & Sorotipos & $\begin{array}{c}\text { Cepas de } \\
\text { L. monocytogenes } \\
\mathrm{N}=13\end{array}$ \\
\hline Cortes cárneos & $4 \mathrm{~b}$ & 6 \\
Ralo & $1 / 2 \mathrm{c}$ & 5 \\
& $1 / 2 \mathrm{a}$ & 2
\end{tabular}

ApaI (New England BioLabs, Beverly, USA). Os produtos da clivagem foram separados em gel de agarose 1\% (Pulsed Field Agarose, BioRad) em tampão TBE 0,5X (0,9M Tris base, 0,9 M ácido bórico, 0,02M EDTA, pH 8,0), por um período de 19 horas $(6 \mathrm{~V} /$ $\mathrm{cm}-1$ ), em equipamento de eletroforese de campo pulsado (CHEFDRIII). 0 tempo de pulso inicial foi de 4 segundos e o tempo final de 40 segundos. A cepa padrão de Salmonella Braenderup (ATCC BAA-664), clivada com a enzima XbaI (Roche Diagnostics), serviu como referência de tamanho dos fragmentos gerados. Após a corrida, o gel foi corado em solução de brometo de etídio $(10 \mathrm{mg} / \mathrm{mL})$ diluída (1:10.000) em água destilada. 0 equipamento Imagequant (Gelifesciences) foi utilizado para capturar as imagens sob luz Ultravioleta. 0 perfil de macro restrição foi analisado visualmente e cada posição de banda foi determinada por comparação com a cepa referência. Isolados com uma banda de diferença foram considerados como sendo de pulsotipos diferentes (Ferronatto et al. 2012). A análise dos cluster e a construção do dendograma foram realizadas utilizando o software BioNumerics versão 4.0 (Applied Maths, Bélgica), utilizando o método UPGMA e o coeficiente de Dados com um índice de tolerância de 1,5\%.

\section{RESULTADOS E DISCUSSÃO}

Isolamento bacteriano em amostras de cortes cárneos bovinos, swabs de carcaças bovinas e ambiente de abatedouros frigoríficos de bovinos

Das 125 amostras de cortes cárneos bovinos comercializados no Distrito Federal analisados foram detectados 11 $(8,9 \%)$ cepas de Listeria monocytogenes. Das 45 amostras de swabs obtidos de meias carcaças bovinas de abatedouros frigoríficos de bovinos localizados no Distrito Federal nenhuma cepa de Listeria monocytogenes foi encontrada, e das 43 amostras de swabs obtidas de ambiente de abatedouros frigoríficos de bovinos foram isoladas duas (2) cepas de Listeria monocytogenes, ambas oriundas de ralos de escoamentos.

Em relação às detecções de L. monocytogenes obtidas em cortes cárneos bovinos os resultados encontrados no 
presente estudo foram similares aos observados por Rocha (2008) em que encontraram $4(11,4 \%)$ L. monocytogenes em 35 amostras de carne bovina homogeneizadas, comercializadas a granel no Distrito Federal. Os resultados deste estudo também se assemelham aos conduzidos por Mantilla et al. (2007), onde encontraram duas $(6,7 \%)$ amostras positivas para L. monocytogenes em 30 amostras de carnes moídas analisadas no município de Niterói, Rio de Janeiro. Novaes et al. (2014) encontraram resultado similares ao deste estudo, de presença de uma (1) $(4,55 \%)$ cepa de $L$. monocytogenes, em 50 amostras de carpacio, no município de Niterói, Rio de Janeiro e os resultados relatados por Yucel et al. (2005) em Ankara, Turquia, em que esses autores também encontraram uma (1) (5.2\%) amostras positivas para L. monocytogenes. Entretanto Kasnowski (2004) encontrou uma alta porcentagem de de cepas de Listeria monocytogenes, 30,1\% em 30 amostras de carnes bovinas no Rio de Janeiro, e Mena et al. (2004) em Portugal, 3 (17,7\%) em 17 amostras de carne. Várias são as possibilidades de contaminação por Listeria monocytogenes dos cortes cárneos bovinos, podendo ser no momento da desossa, no setor de cortes, na câmara fria, durante o transporte e até mesmo dentro dos supermercados. Caselani et al. (2013) relataram em seu estudo que o setor de cortes apresentou ser o ponto com maior contaminação em um matadouro frigorífico, com $10(18,9 \%)$ amostras positivas para Listeria spp., dentre os 53 swabs analisados da sala de corte e em segundo lugar a sala de desossa, com 18,4\% (21) de amostras positivas, em um total de 114 amostras de swa$b s$ ambientais da sala de desossa analisadas. Peccio et al. (2003) não isolaram nenhuma cepa de L. monocytogenes em câmara fria em abatedouros frigoríficos de carnes suína e bovina, no entanto foram encontradas em máquinas de picar carne e trituradores, em instalações de processamento de carnes suína, e em facas utilizadas em matadouro frigoríficos de bovinos. Gudbjörnsdóttir et al. (2004) em estudo conduzido nos Países Nórdicos, detectaram que as correias transportadoras de carcaças e os carrinhos de transporte eram os locais com maior contaminação de Listeria monocytogenes. Os resultados obtidos nesta etapa deste estudo demonstram que há contaminações por Listeria monocytogenes em cortes cárneos bovinos, evidenciando a necessidade de realizações de maiores pesquisas na cadeia de processamento deste produto.

Em relação às detecções de L. monocytogenes obtidas de swabs de carcaças bovinas, Matos et al. (2013) também não encontraram nenhuma cepa de L. monocytogenes em 100 swabs de carcaças analisadas, em um abatedouro frigorífico de carne bovina localizado no interior do Estado de São Paulo. Silveira (2010) observaram que em 110 swabs de carcaças bovinas analisadas na região serrana do Rio Grande do Sul, nenhuma carcaça bovina era positiva para Listeria monocytogenes, no entanto em swabs realizados em etapa anterior a esfola, ou seja, na superfície da pele, 4 superfícies de peles de distintas carcaças $(3,63 \%)$ foram positivas para Listeria monocytogenes. Os resultados obtidos por Picchi et al. (1999) foram diferentes aos encontrados neste trabalho, pois estes autores detectaram L. monocytogenes em (5) 20\% de quartos dianteiros bovinos, originá- rios de matadouros-frigoríficos mantidos sob Inspeção Federal permanente. A ausência de Listeria monocytogenes observada neste estudo não permite afirmar que essa bactéria não ocorra nas carcaças de bovinos, tendo em vista pesquisas que evidenciam a presença deste microrganismo na superfície da pele de bovinos. Os resultados negativos provavelmente se devem ao pequeno número de carcaças amostradas. Um maior número de carcaças deve ser analisadas, bem como um maior número de indústrias frigoríficas.

Em relação aos resultados das detecções de swabs ambientais de abatedouro frigorifico, Lambertz et al. (2013) encontraram uma $(3,8 \%)$ cepa de L. monocytogenes em 26 amostras de ambientes em plantas de processamento de carne bovina, e Silveira (2010) identificou uma cepa de Listeria monocytogenes entre as 200 amostras analisadas na região serrana do Rio Grande do Sul. Entretanto estudos realizados por Caselani et al. (2013), em um matadouro frigorífico de bovinos localizado em Barretos-SP, verificaram que das 411 amostras de swabs ambientais, 21 (5,1\%) amostras de swabs foram positivas para L. monocytogenes e dentre essas, $8(5,8 \%)$ cepas de Listeria monocytogenes foram oriundas do ralo. Peccio et al. (2003) ao analisarem amostras de superfícies de ambiente e equipamentos em abatedouros frigoríficos de Suíno e bovino no Nordeste da Itália, detectaram L. monocytogenes em 6,5\% das amostras, sendo todas as cepas isoladas das facas. Apesar do reduzido número de amostras analisadas neste estudo, a presença desta bactéria nos ralos de escoamento em ambiente de abatedouros frigoríficos de bovino analisados no presente estudo sugerem possíveis falhas na realização adequada dos procedimentos de limpeza e sanitização. Maiores estudos devem ser conduzidos para se verificarem os principais focos de contaminação em plantas de abatedouros frigoríficos de bovinos.

\section{Sorotipificação pela técnica da reação em cadeia da po- limerase em cepas de Listeria monocytogenes isoladas de cortes cárneos bovinos e ambientes de abatedouros frigoríficos}

Os sorotipos encontrados, dentre as treze (13) cepas de Listeria monocytogenes isoladas neste estudo, seis (6) cepas foram do sorotipo $4 \mathrm{~b}$ isoladas das amostras de cortes cárneos bovinos, cinco (5) cepas do sorotipo 1/2c isoladas das amostras de carnes bovinos e duas (2) cepas do sorotipo $1 / 2$ a isoladas dos ralos dos ambientes da indústria frigorífica. Os resultados com os sorotipos e a origem das cepas isoladas neste estudo encontram-se no Quadro 2. Na Figura 1 encontram-se alguns dos resultados das reações por PCRs para identificação das cepas isoladas de cortes cárneos bovinos, e das cepas oriundas dos ralos dos ambientes de abatedouros frigoríficos no Distrito Federal.

Os resultados observados neste estudo, em que o sorotipo $4 \mathrm{~b}$ foi o mais encontrado, seguido pelo segundo sorotipo 1/2c e 1/2a, foram similares aos observados por Hofer et al. (2006), em que encontraram em seus estudos uma maior porcentagem do sorotipo $4 \mathrm{~b}$ com (60,3\%) em 255 cepas de Listeria monocytogenes isoladas de materiais clínicos du- 


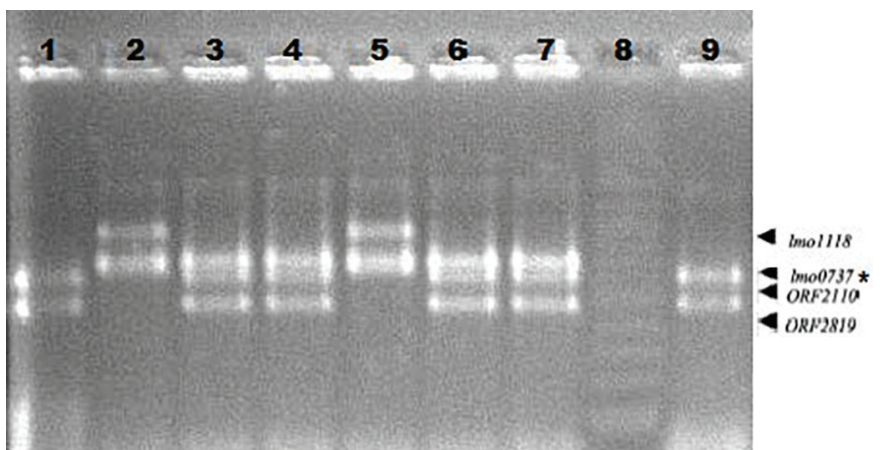

Fig.1. Resultado da PCR para identificação dos sorotipos de Listeria monocytogenes isolados de cortes cárneos e swabs de abatedouro frigorifico no Distrito Federal. 1) cepa de referência para o sorotipo 4b oriunda da FIOCRUZ-RJ (471pb e 597pb); 2 ) cepa de referencia para o sorotipo $1 / 2$ c oriunda da Fiocruz-RJ (691pb e 906pb); 3,4,6 e 7) fragmentos da dupla amplificação do fragmento de DNA lmo0737 (691 pb), sorogrupo IVb-V1 isoladas de cortes cárneos (*); 5) sorotipo $1 / 2 \mathrm{c}(691 \mathrm{pb}$ e 906pb); 8) $100 \mathrm{bp}$ DNA ladder; 9) sorotipo 4b ( 471pb e $597 \mathrm{pb}$ ). Visualização em transiluminador Imagequant (Gelifesciences) em gel de agarose a $2 \%$ com concentração de $5 \mathrm{mg} / \mathrm{ml}$ de brometo de etídio.

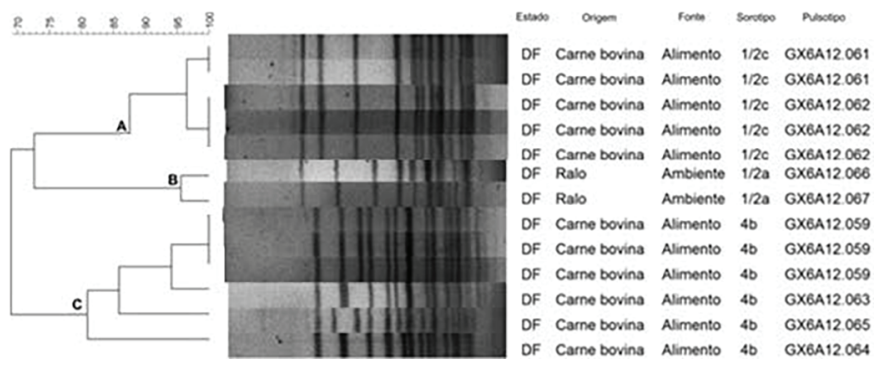

Fig.2. Dendrograma obtido pelo método UPGMA com coeficiente de Dice e índice de tolerância de 1,0\%. Eletroforese de Campo Pulsado (Pulsed-field gel electrophoresis - PFGE) realizado com a enzima de restrição ApaI (Roche Diagnostics) para as 13 cepas de Listeria monocytogenes isoladas em cortes cárneos bovino e swabs de ralo em abatedouro frigoríficos de bovinos no Distrito Federal.

rante os anos de 1969 a 2000, em diferentes regiões pelo método de antissoros somáticos e flagelares policlonais polivalentes e monovalentes produzidos pelo Laboratório de Zoonoses Bacterianas, Instituto Oswaldo Cruz/Fiocruz, RJ. Entretanto em um estudo feito por Camargo (2013) em instalações de processamento de carne, em Viçosa, MG, demonstrou por PCR multiplex que o sorotipo mais encontrado foi o 1/2c e Kramarenko et al. (2013) encontraram em diferentes tipos de alimentos na Estônia, $73,6 \%$ do sorotipo $1 / 2$ a, seguido do sorotipo 4 b com $7,7 \%$ e $7,4 \%$ do sorotipo $1 / 2 \mathrm{~b}$ e $1 / 2 \mathrm{c}$. No trabalho realizado por Shi et al. (2015) também encontraram resultados diferentes com 37 cepas $(46,25 \%)$ de L. monocytogenes pertencentes ao sorotipo $1 / 2$ a e $3 a$, sendo 21 isolados (26,25\%) pertencentes ao sorotipo $4 \mathrm{~b}, 4 \mathrm{~d}$ e $4 \mathrm{e}, 17$ isolados pertenciam ao sorotipo $1 / 2 \mathrm{~b}, 3 \mathrm{~b}$ e 5 isolados $(6,25 \%)$ pertenciam ao sorotipo $1 / 2 \mathrm{c}$ e $3 \mathrm{c}$ em amostras de alimentos "ready-to-eat" em 24 diferentes cidades na China. A identificação de cepas de Listeria monocytogenes pertencentes ao sorogrupo $4 \mathrm{~b}$ no presen- te estudo é relevante devido ao seu potencial patogênico e associação com casos e surtos de listeriose segundo os autores Gerner-Smidt et al. (2006).

Entre as cepas 4b, 3 cepas tiveram uma dupla amplificação do fragmento de DNA lmo0737 ( 691 pb), denominado por Leclercq et al. (2011) de 'profile IVb variant 1' (IVb-v1) (Fig.1). No mesmo estudo feito por Leclercq et al. (2011) eles aplicaram o método de sorotipagem por PCR para cerca de 9000 cepas de Listeria monocytogenes, destes, 22 cepas oriundas da Argélia, Brasil, França e Suíça exibiram também esse novo perfil atípico de sorogrupo IVb e concluíram que essas cepas com perfil de sorogrupo IVb-v1 não parecem ter uma origem clonal recente pois não é uma estirpe emergente, tal como foi observado no estudo realizado por Leclercq et al. (2011) em uma cepa isolada em 1959 na Suiça, a partir da coleção de culturas do Centro de Referência Nacional e da OMS-CC para Listeria (Coleções de Listeria do Instituto Pasteur, CLIP).

\section{Teste de susceptibilidade antimicrobiana}

Dentre as 11 cepas de L. monocytogenes encontradas em cortes cárneos bovino, uma $(9,1 \%)$ cepa apresentou resistência a eritromicina, outra $(9,1 \%)$ cepa a gentamicina e outra a ciprofloxacina $(9,1 \%)$ e todas as cepas (100\%) apresentaram resistência ao Ác. Nalidíxico. Das duas (2) cepas oriundas de ralos de abatedouro frigorífico, todas $(100 \%)$ apresentaram resistência ao Ác. Nalidíxico e a sulfonamidas, conforme podem ser observados no Quadro 3.

Os perfis antimicrobianos para as cepas de Listeria monocytogenes isoladas mostraram uma baixa porcentagem de cepas resistentes a uma variedade de antibióticos incluindo algumas bases utilizadas na terapia com humanos para tratamento de casos de Listeriose, tais como a Penicilina e Gentamicina (Quadro 3). Enquanto a maioria dos isolados foi sensível a todos os antimicrobianos analisados (Quadro 3), apenas uma cepa demonstrou resistência à gentamicina que é a opção de tratamento recomendado para casos de listeriose durante a gravidez (janakiraman 2008). Em estudos realizados por Wieczorek et al. (2012) em L. monocytogenes isoladas de couros e carcaças bovinas, os autores encontraram também uma baixa porcentagem de cepas resistentes à Gentamicina com apenas $1(1,9 \%)$. Khen et al. (2015) também encontraram uma baixa porcentagem de cepas resistentes a esse antibiótico, de 73 cepas analisadas em Dublin, na Irlanda apenas 4 (5\%) apresentaram resistência a essa droga.

Apesar da baixa porcentagem de resistência antimicrobiana observada neste estudo, foi verificado que ela está presente nos microrganismos isolados neste estudo. Não se pode afirmar que ela se encontra em baixa prevalência devido ao baixo número de amostras analisadas, entretanto pode-se afirmar que há ocorrência. A presença de cepas de Listeria monocytogenes resistentes aos antimicrobianos utilizados no tratamento da listeriose humana pode levar a um problema para saúde humana, pois esse tipo de bactéria afeta principalmente imunossuprimidos, idosos, crianças e mulheres grávidas (Mantilla et al. 2007). São necessários mais estudos para uma melhor compreensão da presença 
Quadro 3. Resistência antimicrobiana realizado de Listeria monocytogenes isoladas no Distrito Federal

\begin{tabular}{|c|c|c|c|c|c|c|}
\hline \multirow[t]{2}{*}{ Agente antimicrobiano } & \multicolumn{3}{|c|}{$\begin{array}{l}\text { Cepas isoladas de cortes } \\
\text { cárneos bovinos }(n=11)\end{array}$} & \multicolumn{3}{|c|}{$\begin{array}{c}\text { Cepas isoladas de swabs de ralo de } \\
\text { abatedouro frigorífico de bovinos }(n=2)\end{array}$} \\
\hline & $\mathrm{S}$ & I & $\mathrm{R}$ & $\mathrm{S}$ & I & $\mathrm{R}$ \\
\hline Amoxicilina & $11(100 \%)$ & 0 & 0 & $2(100 \%)$ & 0 & 0 \\
\hline Cefalosporina & $11(100 \%)$ & 0 & 0 & $2(100 \%)$ & 0 & 0 \\
\hline Ciprofloxacino & $7(63,6 \%)$ & $3(27,3 \%)$ & $1(9,1 \%)$ & $1(50 \%)$ & $1(50 \%)$ & 0 \\
\hline Cloranfenicol & $11(100 \%)$ & 0 & 0 & $2(100 \%)$ & 0 & 0 \\
\hline Eritromicina & $10(90,9 \%)$ & 0 & $1(9,1 \%)$ & $2(100 \%)$ & 0 & 0 \\
\hline Gentamicina & $10(90,9 \%)$ & 0 & $1(9,1 \%)$ & $2(100 \%)$ & 0 & 0 \\
\hline Ác. Nalidíxico & 0 & 0 & $11(100 \%)$ & 0 & 0 & $2(100 \%)$ \\
\hline Norfloxacina & $9(81,8 \%)$ & $2(18,2 \%)$ & 0 & $2(100 \%)$ & 0 & 0 \\
\hline Penicilina & $11(100 \%)$ & 0 & 0 & $2(100 \%)$ & 0 & 0 \\
\hline Sulfonamidas & $3(27,3 \%)$ & 0 & $8(72,7 \%)$ & 0 & 0 & $2(100 \%)$ \\
\hline Tetraciclina & $11(100 \%)$ & 0 & 0 & $2(100 \%)$ & 0 & 0 \\
\hline Vancomicina & $11(100 \%)$ & 0 & 0 & $2(100 \%)$ & 0 & 0 \\
\hline
\end{tabular}

desta resistência em cepas de Listeria monocytogenes bem como identificar a real fonte de origem da resistência antimicrobiana.

\section{Analises de PFGE}

Baseado nas análises de macrorestrição por PFGE obtidos com a enzima de restrição Apal, os isolados de L. monocytogenes resultaram em 13 pulsotipos, e mostraram uma divisão em três grupos clonais, segundo o BioNumerics software version 4.0 (Applied Maths, Belgium) , que faz a correlação entre os perfis genéticos obtidos com a enzima de restrição Apal (Fig.2) com um valor de corte mínimo de $80 \%$ de similaridade como proposto por Franciosa et al. (2005). Os isolados foram obtidos de cortes cárneos bovinos comercializados no Distrito Federal e em ralos de ambiente de abatedouro frigorífico. 0 grupo A coincidentemente foi composto por todas as cepas pertencentes ao sorotipo $1 / 2 c$, e apresentou dois perfis genéticos distintos com $87 \%$ de similaridade entre si. 0 grupo B apresentou 2 diferentes pulsotipos com $95 \%$ de similaridade entre si e coincidentemente identificados como pertencentes ao sorotipo $1 / 2$ a. Os isolados do grupo (C) apresentaram quatro perfis genéticos distintos, todos eles coincidentemente pertencentes ao sorotipo $4 \mathrm{~b}$ com similaridade entre si de $80 \%$. Isolados do grupo A e C de um mesmo pulsotipo foram obtidos em diferentes amostras de cortes cárneos bovinos de diferentes regiões do Distrito Federal e isolados do grupo B foram obtidos de diferentes ralos em um mesmo abatedouro frigorifico no Distrito Federal em diferentes épocas de isolamento (Fig.2).

Estudos feito por Gianfranceschi et al. (2009) demonstraram que havia uma correlação quase completa entre os pulsotipos e sorotipos por eles analisados, uma vez que 95,0\% dos seus isolados que obtiveram padrões de PFGE idênticos pertenciam ao mesmo sorotipo, e apenas $5 \%$ de todos os isolados analisados com os mesmos pulsotipos pertenciam a diferentes sorotipos mas pertencentes à mesma linhagem genética. Assemelhando se ao encontrado no presente trabalho em que ocorreram 100\% de correlação entre os pulsotipos e sorotipos analisados. Perfis moleculares determinados por PFGE semelhantes indicam uma possível relação clonal entre os isolados e isso ocorre somente quando ocorre um único evento genético como uma mutação, uma inserção ou deleção, que altere o padrão das bandas (Magalhães et al. 2005, Cruz et al. 2008).

Camargo (2013) identificou em seu trabalho diferentes rotas de contaminação no ambiente de processamento de carne bovina em que isolados com perfis genéticos idênticos foram encontrados em utensílios limpos e sujos, de diferentes cortes finais, e entre utensílios e cortes finais e concluiu que esses resultados analisados em seu trabalho corroborariam com a importância da contaminação cruzada na transmissão desta bactéria dentro de uma planta de processamento da indústria frigorífica. Galvão et al. (2012) também identificaram potenciais vias de contaminação e permanência de cepas nos estabelecimentos por ele avaliado, em que um isolado observado em um estabelecimento de processamento foi obtido a partir do produto final (carne moída) e apresentou uma similaridade de $82 \%$ com outros seis outros isolados, todos obtidos no mesmo estabelecimento em datas anteriores realizados durante um período de 5 meses.

No presente estudo cepas foram observadas a partir de diferentes cortes cárneos bovinos comercializados em diferentes regiões do Distrito Federal, bem como em um abatedouro frigorifico em diferentes épocas de isolamento. Esse resultado pode sugerir uma ampla disseminação destes genótipos no Distrito Federal e uma possível persistência da cepa no ambiente causado por uma falha dos procedimentos de limpeza e sanitização adotados no próprio abatedouro frigorífico. Porém devido ao pequeno número de amostras analisadas maiores estudos precisam ser realizados para que possa se confirmar a correlação entre as origens dessas cepas e sua possível permanecia nos abatedouros frigoríficos.

\section{CONCLUSÕES}

Os resultados encontrados neste trabalho permitem concluir que no período de março de 2014 a janeiro de 2015 foram encontrados a presença de Listeria monocytogenes em cortes cárneos bovinos e em ambientes de abatedouro Frigorifico no Distrito Federal. 
Os principais sorotipos encontrados foram o $4 \mathrm{~b}, 1 / 2 \mathrm{a}$ e $1 / 2$ c.

Dentre as cepas de L. monocytogenes encontradas em cortes cárneos bovinos, ocorreram resistência à eritromicina, gentamicina e ciprofloxacina.

Todas as cepas apresentaram resistência ao ácido nalidíxico.

Das cepas oriundas de ralos de abatedouro frigorífico, todas apresentaram resistência ao ácido nalidíxico e a sulfonamidas.

A análise por eletroforese de campo pulsante (PFGE) resultou em 13 diferentes pulsotipos, e mostraram uma divisão em três grupos que coincidentemente separou os 3 sorotipos, sugerindo uma ampla disseminação destes genótipos no Distrito Federal.

Os resultados ainda sinalizam para que se realizem maiores estudos para verificar a abrangência deste microrganismo nos cortes cárneos bovinos e abatedouros frigoríficos tendo em vista a importância desta bactéria para a saúde publica.

\section{REFERÊNCIAS}

ABNT 1988. Preparo da Amostra para Exame Microbiológico. Associação Brasileira de Normas Técnicas, Rio de Janeiro.

Barbosa A.V., Cerqueira A.M.F., Rusak L.A., Reis C.M.F., Leal N.C., Hofer E. \& Vallim D.C. 2015. Characterization of epidemic clones of Listeria monocytogenes serotype $4 \mathrm{~b}$ isolated from humans and meat products in Brazil. J. Infect. Dev. Ctries.; 9(9):962-969.

Borucki M.K. \& Call D.R. 2003. Listeria monocytogenes serotype identification by PCR. J. Clin. Microbiol. 41:5537-5540.

Borucki M.K., Kim S.H., Call D.R., Smole S.C. \& Pagotto F. 2004. Selective discrimination of Listeria monocytogenes epidemic strains by a mixedGenome DNA microarray compared to discrimination by Pulsed-field gel electrophoresis, Ribotyping, and Multilocus sequence typing. J. Clin. Microbiol. 42(11):5270-5276.

Brasil 2005. Ministério da Agricultura, Pecuária e Abastecimento. Instrução Normativa no 40 de 12 de dezembro de 2005. Aprovar os Métodos Analíticos, Isolamento e Identificação de Salmonella na Carne Bovina, Avicultura e Produtos derivados de Ovos - MLG - 4.03, Metodologia Alternativa de SalmonellaA-Bax -MLG 4C .01, Isolamento e Identificação de Listeria monocytogenes em Carne Vermelha, Carne de Ave, Ovos e Amostras Ambientais, MLG 8.04 - Metodologia Alternativa de Listeria A-BAX MLG-8 A .01, Escherichia coli, MPN AOAC 966.24, Método Petrifilm AOAC 998.08, que passam a constituir Padrões Oficiais para Análise de Microbiologia de Produtos de Origem Animal. DOU, 16/12/2005, seção 1, p.70, 2005.

Camargo A.C. 2013. Caracterização fenotípica e molecular de isolados de Listeria monocytogenes obtidos em uma planta de processamento de carne bovina, em Viçosa, MG. Dissertação de Mestrado, Universidade Federal Viçosa, Minas Gerais.

Cartwright E.J., Jackson K.A., Johnson S.D., Graves L.M., Silk B.J. \& Mahon B.E. 2013. Listeriosis outbreaks and associated food vehicles, United States, 1998-2008. Emerg. Infect. Dis. 19:1-9.

Caselani K., Prata L.F., Bizari P.A., Pereira G.T., Marchi P.G.F. \& Picinato M.A.C. 2013. Ocorrência de Listeria spp. e de Listeria monocytogenes, em um matadouro-frigorífico de bovinos do Estado de São Paulo. Biosci. J., Uberlândia, 29(4):956-961.

Chen Y. \& Knabel S.J. 2007. Multiplex PCR for simultaneous detection of bacteria of the genus Listeria, Listeria monocytogenes, and major serotypes and epidemic clones of L. monocytogenes. Appl. Environ. Microbiol. 73:6299-6304.

CLSI 2012. Methods for Antimicrobial Dilutions and Disk Susceptibility Testing of Infrequently Isolated or Fastidious Bacteria: approved guidiline (M45-A). Vol.26(19). Clinical and Laboratory Standards Institute.
Cruz C.D., Martinez M.B. \& Destro M.T. 2008. Listeria monocytogenes: um agente infeccioso ainda pouco conhecido no Brasil. Alim. Nutr. 19(2):195-206. (ISSN 0103-4235)

Doumith M., Buchrieser C., Glaser P., Jacquet C. \& Martin P. 2004. Differentiation of the major Listeria monocytogenes serovars by multiplex PCR. J. Clin. Microbiol. 42(8):3819-3822.

Ferronatto A.I., Pellegrini D.C.P., Guerra P. \& Cardoso M.R.I. 2012. Distribuição de grupos clonais de Listeria monocytogenes em carcaças e no ambiente de matadouros frigoríficos de suínos. Archs Vet. Sci. 17(3):42-49.

Franciosa G., Maugliani A., Floridi F. \& Aureli P. 2005. Molecular and experimental virulence of Listeria monocytogenes strains isolated from cases with invasive listeriosis and febrile gastroenteritis. FEMS Immunol. Med. Microbio. 43(3):431-439.

Gallegos J.M., Vanegas M.C., Albarracín Y., Máttar S., Poutou R.A. \& Carrascal A.K. 2008. Frequency of isolation of Listeria spp. in different retail foods in Colombia. Anim. Prod. Res. Adv. 4:9-18.

Galvão N.N., Chiarini E., Destro M.T., Aguiar F.M. \& Nero L.A. 2012. PFGE characterisation and adhesion ability of Listeria monocytogenes isolates obtained from bovine carcasses and beef processing facilities. Meat Science 92(4):635-643.

Gerner-Smidt P., Hise K., Kincaid J., Hunter S., Rolando S., Hyytia- Trees E., Ribot E.M. \& Swaminathan B. 2006. PulseNet USA: a five-year update. Foodborne Pathog. Dis. 3:9-19.

Gianfranceschi M.V., D’Ottavio M.C., Gattuso A., Bella A. \& Aureli P. 2009. Distribution of serotypes and pulsotypes of Listeria monocytogenes from human, food and environmental isolates (Italy 2002-2005). Food Microbiol. 26:520-526.

Gudbjörnsdóttir B., Suihko M.L., Gustavsson P., Thorkelsson G., Salo S., Sjöberg A.M., Niclasen 0. \& Bredholt S. 2004. The incidence of Listeria monocytogenes in meat, poultry and seafood plants in the Nordic countries. Food Microbiol. 21:217-225.

Graves L.M. \& Swaminathan B. 2001. PulseNet standardized protocol for subtyping Listeria monocytogenes by macrorestriction and pulsed-field gel electrophoresis. Int. J. Food Microbiol. 65(1/2):55-62.

Hofer E., Reis C.M. \& Hofer C.B. 2006. Serovars of Listeria monocytogenes and related species isolated from human clinical specimens. Revta Soc. Bras. Med. Trop., 39(1):32-37.

Jardim F.B.B., Silva E.N., Okura M.H. \& Ramos M.A. 2006. Influência dos sistemas de pastagem e confinamento na contaminação microbiana de carcaças bovinas. Ciênc. Tecnol. Aliment., Campinas, 26(2):277-282. Disponível em <http://www.scielo.br/scielo.php?script=sci_arttext\&pid=S0101-20612006000200008\&lng=en\&nrm=iso> Acesso em 10 Dec. 2015.

Kasnowski M.C. 2004. Listeria spp., Escherichia coli: isolamento, identificação, estudo sorológico e antimicrobiano em corte de carne bovina (alcatra) inteira e moída. Dissertação de Mestrado em Higiene Veterinária e Processamento Tecnológico de Produtos de Origem Animal, Universidade Federal Fluminense, Niterói. 110p.

Kerouanton A., Marault M., Petit L., Grout J., Dao T.T. \& Brisabois A. 2010a. Evaluation of a multiplex PCR assay as an alternative method for Listeria monocytogenes serotyping. J. Microbiol. Methods 80(2):134-137

Kerouanton A., Roche S.M., Marault M., Velge P., Pourcher A.M., Brisabois A., Federighi M. \& Garrec N. 2010b. Characterization of isolates of Listeria monocytogenes from sludge using pulsed-field gel electrophoresis and virulence assays. J. Appl. Microbiol. 108(4):1380-1388.

Khen B.K., Lynch O.A., Carroll J., McDowell D.A. \& Duffy G. 2015. Occurrence, antibiotic resistance and molecular characterization of Listeria monocytogenes in the beef chain in the Republic of Ireland. Zoonoses and Public Health 62:11-17.

Kramarenko T., Roasto M., Meremäe K., Kuningas M., Põltsama P. \& Elias T. 2013. Listeria monocytogenes prevalence and serotype diversity in various foods. Food Control 30:24-29.

Lambertz S.T., Ivarsson S., Lopez-Valladares G., Sidstedt M. \& Lindqvist R. 2013. Subtyping of Listeria monocytogenes isolates recovered from retail ready-to-eat foods, processing plants and listeriosis patients in Sweden. Int. J. Food Microbiol. 166:186-192.

Leclercq A., Chenal-Francisque V., Dieye H., Cantinelli T., Brisse S., Lecuit 
M. \& Drali R. 2011. Characterization of the novel Listeria monocytogenes PCR serogrouping profile IVb-v1. Int. J. Food Microbiol. 147:74-77.

Lecuit M. 2007. Human listeriosis and animal models. Microbes Infect. 9:1216-1225.

Martin P., Jacquet C., Goulet V., Vaillant V. \& Valk H. 2006. Participants in the PulseNet Europe Feasibility Study Pulsed-Field Gel Electrophoresis of Listeria monocytogenes strains: the PulseNet Europe Feasibility Study. Foodborne Pathog. Dis. 3:303-308.

Magalhães V.D., Ferreira J.C., Barelli C. \& Darini A.L.C. 2005. Eletroforese em campo pulsante em bacteriologia: uma revisão técnica. Rvta Inst. Adolfo Lutz 64(2):155-161.

Mantilla S.P.S., Franco R.M., Oliveira L.A.T., Santos E.B. \& Gouvêa R. 2007. Ocorrência de Listeria spp. em amostras de carne bovina moída comercializadas no município de Niterói, RJ, Brasil. Ciênc. Agrotec., Lavras, 31(4):1225-1230.

Matos A.V.R., Nunes L.B.S., Vianna C., Spina T.L.B., Zuim C.V., Possebon F.S., Xavier D.M., Ferraz M.C. \& Pinto J.P.A.N. 2013. Listeria monocytogenes, E. coli 0157, Salmonella spp. e microrganismos indicadores em carcaças bovinas para exportação. Arq. Bras. Med. Vet. Zootec. vol.65 no.4 Belo Horizonte, Aug. 2013.

Mena C., Almeida G., Carneiro L., Teixeira P., Hogg T. \& Gibbs P.A. 2004. Incidence of Listeria monocytogenes in different food products commercialized in Portugal. Food Microbiol. 21:213-216.

Moreno L.Z., Paixão R., Gobbi D.D.S., Raimundo D.C., Ferreira T.P., Moreno A.M., Hofer E.M.F., Reis C.M.F., Matté G.R. \& Matté M.H. 2014. Characterization of antibiotic resistance in Listeria spp. isolated from slaughterhouse environments, pork and human infections. J. Infect. Dev. Ctries 8(4):416-423.

Novaes S.F., Alves V.O., Lanzarin M., Ritter D.O. \& Franco R.M. 2014. Listeria spp. em carpacio de carne bovina e perfil de resistência aos agentes antimicrobianos. Arq. Inst. Biológico, São Paulo, 81(4):309-314.

Peccio A., Autio T., Korkeala H., Rosmini R. \& Trevisani M. 2003. Listeria monocytogenes occurrence and characterization in meat-producing plants. Lett. Appl. Microbiol., Oxford, 37:234-238.

Picchi V., Ramos S.E.O.T., Souza S.L.P. \& Balian S.C. 1999. Isolamento e identificação de Listeria spp. em quartos dianteiros de bovinos desossados. Higiene Alimentar 13(63):38-42.

PulseNet 2009. The National Molecular Subtyping Network for Foodborne
Disease Surveillance. Standardized Laboratory Protocol for Molecular Subtyping of Listeria monocytogenes by Pulsed Field Gel Electrophoresis (PFGE). Disponível em <http://www.cdc.gov/pulsenet> Acesso em Sept. 5, 2015.

Rocha R.A. 2008. Identificação microbiológica e diferenciação de espécies de Listeria spp. por análise de restrição de fragmentos de PCR (RFLP-PCR) em amostras de carnes e derivados comercializados no distrito federal. Dissertação de Mestrado em Saúde Animal, Universidade de Brasília, Brasília.

Silva N., Junqueira V.C.A. \& Silveira N.F.A. 1997. Manual de métodos de Análise Microbiológica de Alimentos. Varela, São Paulo. 295p.

Silveira J.G. 2010. Investigação de Listeria sp. e microrganismos mesófilos totais em carcaças bovinas e em ambiente industrial de abatedouro frigorífico, Porto Alegre, RS. Dissertação de Mestrado da Universidade Federal do Rio Grande do Sul, Porto Alegre. Disponível em <https:// www.lume.ufrgs.br/bitstream/handle/10183/28738/000772856. pdf?sequence=1> Acesso em 25 abr. 2016.

Scarcelli E. \& Piatti R.M. 2002. Patógenos emergentes relacionados à contaminação de alimentos de origem animal. Inst. Biológico, São Paulo, 64(2):123-127.

Shi W., Qingping W., Jumei Z., Moutong C. \& Zea Y. 2015. Prevalence, antibiotic resistance and genetic diversity of Listeria monocytogenes isolated from retail ready-to-eat foods in China. Food Control 47:340-347.

Troxler R., Von Graevenitz A., Funke G., Wiedemann A. \& Stock I. 2000. Natural antibiotic susceptibility of Listeria species: L. grayi, L. innocua, L. ivanovii, L. monocytogenes, L. seeligeri and L. welshimeri strains. Clin. Microbiol. Infect. 6:525-535.

Vanegas M.C., Vasquez E., Martinez A.J. \& Rueda A.M. 2009. Detection of Listeria monocytogenes in raw whole milk for human consumption in Colombia by real-time PCR. Food Control 20:430-432.

Yucel N., Citak S. \& Onder M. 2005. Prevalence and antibiotic resistance of Listeria species in meat products in Ankara, Turkey. Food Microbiol. 22:241-245.

Wieczorek K., Dmowska K. \& Osek J. 2012. Prevalence, characterization, and antimicrobial resistance of Listeria monocytogenes isolates from bovine hides and carcasses. Appl. Environ. Microbiol. 78:2043-2045.

Wiedmann M. 2002. Molecular subtyping methods for Listeria monocytogenes. J. AOAC Int. 85(2):524-531. 